\title{
MAPEAMENTO DE FRAGILIDADE AMBIENTAL DA BACIA HIDROGRÁFICA DO RIO SAPUCAIA
}

\author{
Alexandre Herculano de Souza Lima ${ }^{(a)}$, Luan Lacerda Ramos ${ }^{(b)}$, Lucas Marcone dos Santos ${ }^{(c)}$ \\ (a) Departamento de Geografia/UFS, Universidade Federal de Sergipe, dandefish@ @otmail.com \\ ${ }^{(b)}$ Departamento de Geografia/UFS, Universidade Federal de Sergipe, luan_ramos1@ @otmail.com \\ ${ }^{(c)}$ Departamento de Geografia/UFS, Universidade Federal de Sergipe, lukasmarcony @ hotmail.com
}

\author{
Eixo: GEOTECNOLOGIAS E MODELAGEM ESPACIAL EM GEOGRAFIA \\ FÍS IC A
}

\begin{abstract}
Resumo
O mapeamento de fragilidade ambiental auxilia tanto na gestão territorial como na contribuição de conhecimentos para os vários ramos da ciência que se empenham em trabalhar com propostas ambientais. Esta metodologia busca por sintetizar dados quantitativos que são os graus de fragilidade atribuídos a cinco mapeamentos prévios: uso da terra e cobertura vegetal, dissecação do relevo, classes de solo e declividade. Como as bacias hidrográficas são reconhecidas como unidades de planejamento e gestão por leis federais e estaduais, este artigo objetivou realizar um mapeamento de fragilidade ambiental com apoio de sistema de informações geográficas para a bacia costeira do Rio Sapucaia.
\end{abstract}

Palavras chave: Rio Sapucaia, fragilidade ambiental, geoprocessamento, bacia hidrográfica.

\section{Introdução}

Por tratarem-se de unidades de planejamento, as bacias hidrográficas carecem de instrumentos de análise e gestão ambiental. Bacias costeiras como a do Rio Sapucaia, são ainda mais relevantes neste contexto dada a interação entre o ambiente fluvial e marinho (CURTARELLI, 2009).

No que se refere a pertubações ou impactos ambientais, existem diversas perspectivas para se análisar o meio ambiente. Desta maneira, o presente estudo busca por trazer um conceito de fragilidade ambiental pautado no ponto de vista geomorfológico, contando com a análise de aspectos naturais da paisagem e com a intervenção pela ação do homem. Os estudos geomorfológicos são imprescindíveis para a analise de eventos como erosões, inundações, instabilidades de terreno, movimentos de massas, possiblitando o auxilio na identificação das potencialidade e fragilidades naturais, dos terrenos conforme os seus variados usos e ocupações (SANTOS e SOBREIRA, 2008).

A partir da resolução no 25/2015 do Conselho Estadual de Recurso Hídricos o estado de Sergipe passa oficialmente a adotar uma nova divisão hidrográfica, esta engloba duas novas bacias hidrográficas, a Bacia Costeira do Rio Sapucaia e Bacia Costeira do Caueira-Abaís (GOVERNO DE SERGIPE, 2015). 


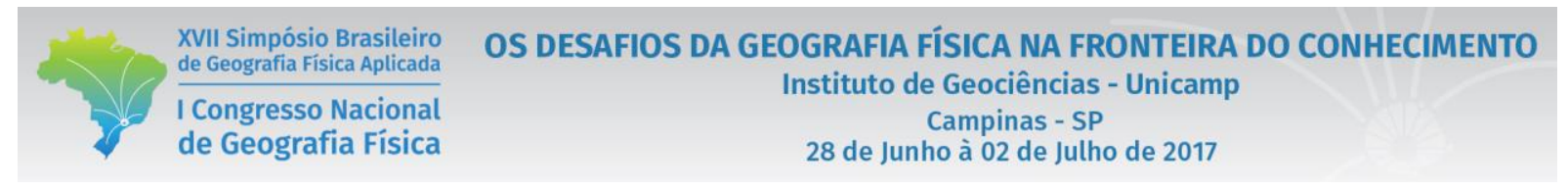

Nesta perspectiva, o objetivo deste trabalho foi realizar um mapa de fragilidade ambiental para Bacia do Rio Sapucaia com o intuito de oferecer subsídios informativos, uma vez que trata-se de uma temática ainda pouco discutida no estado.

\section{2. Área de estudo}

A Bacia Hidrográfica do Rio Sapucaia é englobada totalmente pelo estado de Sergipe, situa-se entre os municípios de Pirambu e Japaratuba, sua foz esta localizada entre as desembocaduras dos rios Japaratuba e São Francisco, e com os seguintes pontos de extremidade territorial: $10^{\circ} 36^{\prime} 19^{\prime \prime} \mathrm{S}$ de latitude ao norte, $10^{\circ} 44^{\prime} 24^{\prime \prime} \mathrm{S}$ de latitude ao Sul, $36^{\circ} 54^{\prime} 8^{\prime \prime} \mathrm{O}$ de longitude ao oeste e $36^{\circ} 44^{\prime} 10 \mathrm{O}$ de longitude ao leste (Figura 1).

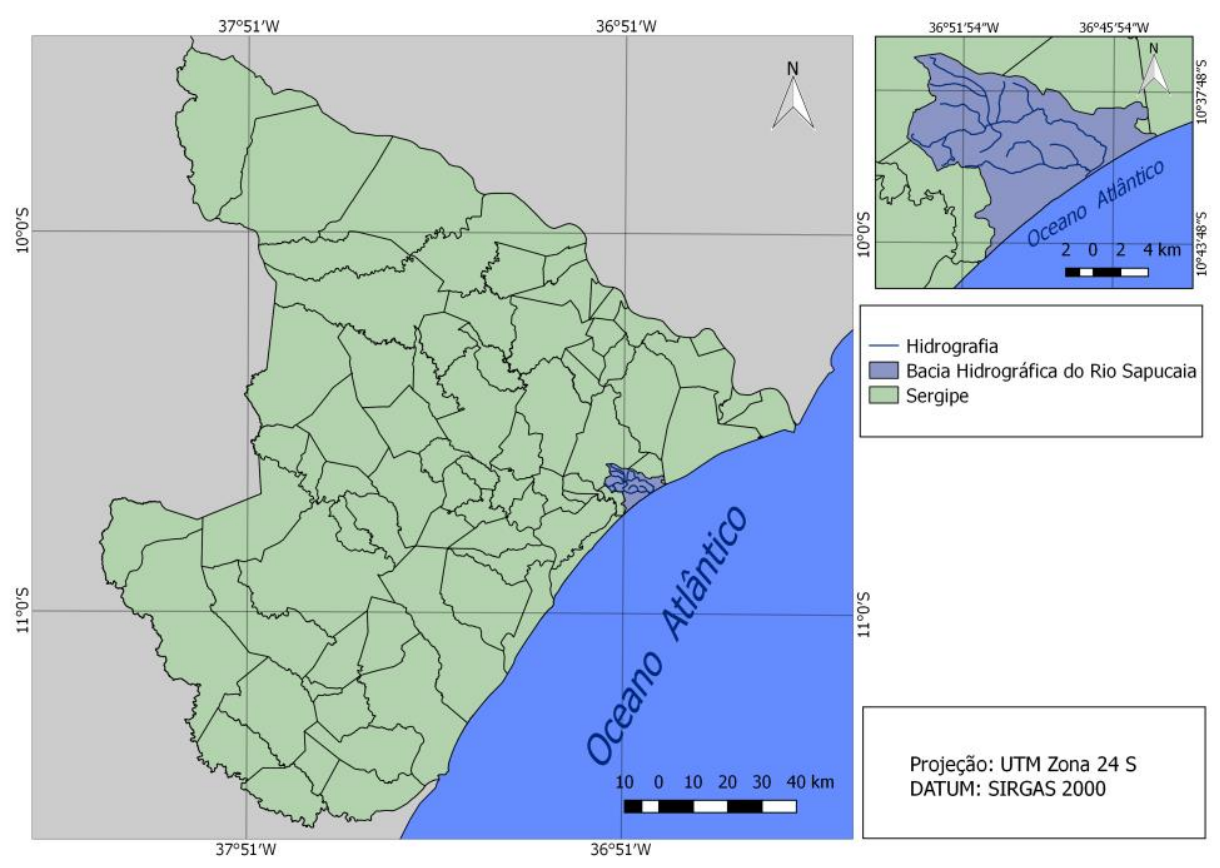

Figura 1. Localização da área de estudo. Fonte: SRH/SE (2016); IBGE (2015).

\section{Materiais e métodos}

Este trabalhou teve como ponto de partida uma bibliografia para fundamentar o conhecimento teóricometodógico necessário à pesquisa. Em seguida iniciou-se a obtenção de arquivos a serem processados no Sistema de Informação Geográfica (SIG) ArcGIS 10.3. Por fim, foram analisados os dados gerados através da confecção deste artigo. 
A fundamentação teórica para embasar os prodecimentos metodológicos seguiu a proposta de ROSS (1994). De acordo o autor o mapa de fragilidade ambiental é uma síntese de quatro outros mapas (uso da terra, classes de solo, declividade e dissecação do relevo) aos quais são atribuídos os seguintes graus de fragilidade ambiental: 1 - Muito Baixa. 2 - Baixa; 3 -Média; 4 -Forte; 5 - Muito Forte.

Através do sítio do TOPODATA (Banco de Dados Geomorfométricos do Brasil) do INPE (Instituto Nacional de Pesquisas Espaciais) foi adquirido o modelo digital de elevação que compreende a área de estudo. Este produto posteriormente foi recortado de acordo com os limites da bacia hidrográfica do Rio Sapucaia e reprojetado para datum SIRGAS 2000 na projeção UTM zona 24S.

O mapa de declividade classificado foi elaborado a partir do modelo digital de elevação, para efetuação deste procedimento, foi utilizada a ferramenta slope. Os índices de fragilidade ambiental atribuídos aos graus de declividade foram classificados segundo a proposta de ROSS (1994).

O vetor das classes de solo foi cedido pela Empresa Brasileira de Pesquisa Agropecuária (EMBRAPA). Após aquisição foram atribuídas às classes de solos os respectivos graus de fragilidade ambiental.

A elaboração do mapa de dissecação do relevo contou inicialmente com a geração de uma malha vetorial com quadrículas de $1 \mathrm{Km}^{2}$ recobrindo toda a área de estudo. Feito isso, foram atribuídas as informações de altitude mínima, média e máxima para cada quadricula sendo utilizada a seguinte fórmula proposta por EVANS (1972):

$$
\mathrm{d}=(\mathrm{z}-\mathrm{z}(\min )) /(\mathrm{z}(\max )-\mathrm{z}(\min ))
$$

Sendo: $\mathrm{d}=$ dissecação; $\mathrm{z}=$ altitude.

Para dissecação horizontal optou-se pela utilização da densidade de drenagem, que com a mesma malha usada para dissecação vertical foram atrelados os valores da soma dos comprimentos de drenagem compreendidos pelo espaço de cada quadrícula. ROSS (1994) apesar de recomendar o uso da densidade de drenagem, atribui os graus de fragilidade apenas para dimenssões interfluviais, para resolver esta questão foram relacionados graus fragilidade à classificação de densidade de drenagem proposta por VILLELA e MATTOS (1975).

Com os índices de dissecação horizontal e vertical calculados, foi feita uma integração dos dois valores e em seguida a classificação conforme os padrões estabelecidos pela metodologia proposta.

O mapa de uso da terra e cobertura vegetal foi confeccionado por meio do uso de métodos de classificação supervisionada de imagem de satélite. A imagem utilizada foi obtida através do sítio do Instituto Nacional 


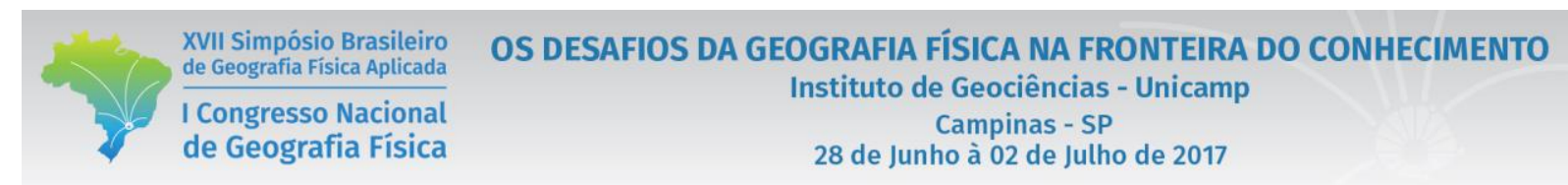

de Pesquisas Espaciais (INPE), sendo utilizadas as imagens CBERS 4 dos sensores PAN5 e MUX. Com as bandas do sensor MUX foi feita uma composição de cor-natural e posteriormente uma fusão com a banda do sensor PAN5 para melhorar a resolução geométrica. Após a conclusão destes procedimentos foi feita uma relação dos tipos de uso da terra e cobertural vegetal com os graus de fragilidade.

Para chegar-se ao produto final desta pesquisa foi feita uma sobreposição ponderada com os quatro mapas confeccionados previamente utilizando-se a ferramenta weighted overlay. Foram atribuídos níveis 25\% de influência para cada mapeamento sobre o mapa de fragilidade ambiental.

\section{Resultados e discussão}

O mapa de fragilidade amnbiental apresentou o predomínio do grau de fragilidade médio em sua maior parte, este fato ocorreu devido a combinação dos mapas de uso da terra e de classes de solo que apresentaram níveis de fragilidades altos e muitos altos contrastados com o mapa de declividade no qual destacaram-se áreas planas que possuem graus de fragilidade muito baixos.

Algumas pequenas áreas apresentaram grau fragilidade alto relacionado com a somatização dos relevos dissecados, os neossolos e das declividades presentes nas áreas de entalhamento dos canais de drenagem mais expressivos.

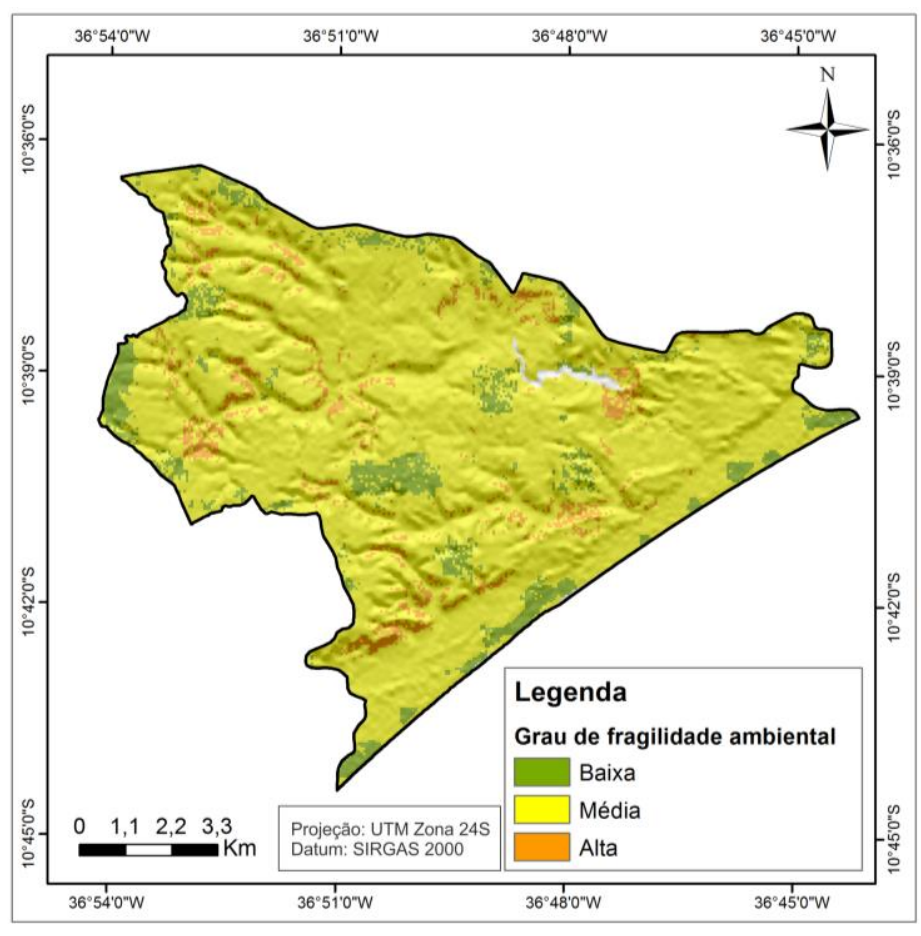

Figura 2 - Mapa de fragilidade ambiental da bacia hidrográfica do Rio Sapucaia. Fonte: SRH/SE (2016); INPE (2016); EMBRAPA (1975). 


\section{Conclusão}

A metodologia de fragilidade ambiental demonstrou bons resultados pautados em análises quantitativas automatizadas via SIG que permitem o auxilio na gestão de unidades territoriais como as bacias hidrográficas visando o cuidado com setores mais susceptíveis a perturbações ambientais, que no caso da bacia hidrográfica do Rio Sapucaia são os setores de alto grau de fragilidade.

\section{Bibliografia}

BRASIL. Política Nacional dos Recursos Hídricos. Lei n. ${ }^{\circ}$ 9.433, de 8 de janeiro de 1997.

CHRISTOFOLETTI, A. Geomorfologia. 2a ed. São Paulo: Edgard Blücher, 1980.

CURTARELLI, M. P. SIG aplicado à caracterização morfométrica de bacias hidrográficas - estudo de casoda bacia hidrográfica do rio Cubatão do Sul - Santa Catarina/Brasil. Anais do XIV Simpósio Brasileiro de Sensoriamento Remoto, Natal; INPE, 2009. 6 p.

DONHA, A. G.; SOUZA, L. C. de P.; Sugamosto, M. L.; Lima, V. C. Avaliação da metodologia utilizada na geração dos mapas de fragilidade ambiental em uma área piloto na APA do Iraí. In: IV Seminário do Projeto Interdisciplinar sobre Eutrofização de Águas de Abastecimento Público na Bacia do Altíssimo Iguaçu, Curitiba-PR, 2003.

FLORENZANO, Tereza G. (org.). Geomorfologia: conceitos e tecnologias atuais. São Paulo: Oficina de Textos, 2008.

ROSS, J. L. S. Análise empírica da fragilidade dos ambientes naturais e antropizados. In: Revista do departamento de geografia, no 8. FFLCH. USP. São Paulo. 1994. 
SANTOS, C. A.; SOBREIRA, F. G. Análise morfométrica como subsídio ao zoneamento territorial: o caso das bacias do Córrego Carioca, Córrego do Bação e Ribeirão Carioca na região do Alto Rio das Velhas - MG. Revista Escola de Minas, v.61, p.77-85, 2008.

SPÖRL, C.; ROSS, J. L. S. Análise comparativa da fragilidade ambiental com aplicação de três modelos.

Súmula da 10. Reunião Técnica de Levantamento de Solos. Rio de Janeiro:1979. 83p. GOVERNO DE SERGIPE.

Resolução $\mathbf{n}^{0}$ 25, de novembro de 2015. Estabelece a divisão hidrográfica de Sergipe para implementação da Política Estadual de Recursos Hídricos e atuação do Sistema Estadual de Gerenciamento de Recursos Hídricos. 2015.

VILLELA, S.M.; MATTOS, A. Hidrologia aplicada. McGraw-Hill do Brasil, São Paulo, 1975, p.245. 